\title{
RESSIGNIFICAÇÕES DO PROFESSOR DE LÍNGUA PORTUGUESA ACERCA DO AGIR DIDÁTICO COM GÊNEROS
}

\author{
Alana Cerqueira Paranhos Capitó ${ }^{1}$, Camila Santos Ferreira ${ }^{1} \&$ Gustavo Lima $^{l^{*}}$
}

\begin{abstract}
RESUMO
CAPITÓ; A. C. P.; FERREIRA, C. S.; LIMA, G. Ressignificações do professor de língua portuguesa no agir didático com gêneros. Perspectivas Online: Humanas \& Sociais Aplicadas, v.10, n.28, p.80-97, 2020.

Os impactos dos estudos sobre gênero nas práticas escolares e no processo de elaboração de documentos oficiais de ensino e de materiais didáticos são evidentes. Desde a publicação dos PCN, no final do século passado, tem crescido significativamente o número de propostas curriculares que atribuem ao gênero um lugar de destaque no ensino de língua materna. Nesse sentido, o ensino na perspectiva dos gêneros parece mesmo um fenômeno irreversível. Em meio a isso, professores têm se inquietado em relação ao que e como devem ensinar gêneros. Assim, este artigo busca investigar como o professor de língua portuguesa tem

teórico é constituído por alguns estudos no âmbito da didática das línguas, como os de Schneuwly e Dolz (2004) e Lima (2016), numa interface com a clínica da atividade (AMIGUES, 2004; CLOT,2007), com vistas a compreender melhor a natureza do trabalho com gêneros na sala de aula sob a perspectiva docente. Os dados foram obtidos através da colaboração de duas professoras por meio de entrevista e verbalizações em sessões de autoconfrontação simples. Os resultados apontam para algumas categorias de ressignificação do agir didático com gêneros nas práticas de ambas as professoras.
\end{abstract} ressignificado esse ensino. $\mathrm{O}$ nosso aporte

Palavras-chave: Autoconfrontação Simples; Ensino; Gênero textual; Ressignificação. 


\title{
RESSIGNIFICATIONS OF THE PORTUGUESE LANGUAGE TEACHER IN THE ACTION OF TEACHING WITH GENDERS
}

\begin{abstract}
The impacts of genres studies on school practices and the process of preparing official teaching documents and teaching materials are evident. Since the publication of the PCN, at the end of the last century, the number of curricular proposals that attribute genre to a prominent place in the language teaching has grown significantly. In this sense, teaching from a genre perspective seems to be an irreversible phenomenon. In the midst of this, teachers have been concerned about what and how they should teach genres. Thus, this article aims to investigate how teachers have ressignified genre teaching. Our theoretical

framework is based on the some studies in the field of language teaching, such as those by Schneuwly and Dolz (2004) and Lima (2016), in an interface with the activity clinic (AMIGUES, 2004; CLOT, 2007), with a view to to better understand the nature of genre teaching in the classroom from a perspective of the teachers. The data were obtained through the collaboration of two teachers through interviews and verbalizations in simple self-confrontation sessions. The results point to some categories of re-signify the didactic action with genres in the practices of both teachers.
\end{abstract}

Keywords: Resignification; Simple self-confrontation; Teaching; Textual genre.

\footnotetext{
${ }^{1}$ Universidade Federal do Agreste de Pernambuco. Av. Bom Pastor, s/n, Boa Vista, Garanhuns, PE, 55292-270. Brasil; $(*)$ e-mail: ghlima.prof@gmail.com

Data de recebimento: 01/05/2020. Aceito para publicação: 15/06/2020. Data da publicação: 22/06/2020.
}

Persp. Online: hum \& sociais aplicada., Campos dos Goytacazes, 28 (10)80-97- 2020 seer.perspectivasonline.com.br 


\section{INTRODUÇÃO}

A definição acerca de quais objetos de ensino precisam ser tomados como alvo de reflexão mais sistemática no ensino de língua perpassa, inevitavelmente, por uma discussão mais ampla sobre os propósitos que lhes são estabelecidos. De acordo com Dolz, Gagnon e Decândio (2009, p. 28), as finalidades de ensino de uma língua são três: "comunicar de maneira adequada, refletir sobre a comunicação e sobre a língua bem como construir referências culturais"

A primeira finalidade está relacionada à necessidade de o aluno produzir e compreender textos de diferentes esferas discursivas como forma de inserção nas práticas sociais. A segunda finalidade envolve o desenvolvimento da consciência linguística, ou seja, da capacidade de o aluno refletir sobre o sistema da língua e suas múltiplas formas de manifestação. Por fim, a terceira e última finalidade deve considerar o componente cultural da língua, de forma a garantir o acesso à história, aos valores e aos bens simbólicos de prestígio na sociedade.

Assim, considerando as finalidades acima elencadas, a delimitação do que será tomado como objeto de reflexão sistemática no ensino de língua consiste em uma tarefa árdua, pois envolve não só a natureza multifacetada dos fenômenos linguísticos, mas também questões de ordem social, política e ideológica. Essa tensão, gerada em função das variáveis envolvidas, leva à questão dos objetos de ensino, os quais devem ser pensados em três dimensões complementares: "ao repertório linguístico de referência estabelecido pelos currículos, às capacidades linguageiras a serem desenvolvidas pelos alunos e aos saberes que devem construir sobre a língua" (DOLZ; GAGNON; DECÂNDIO, 2009, p.31).

No que concerne à abordagem de ensino de língua pautada na diversidade de gêneros, foco deste estudo, essa tensão resulta justamente do processo de sedimentação dos saberes escolares nas práticas de ensino (SCHNEUWLY; CORDEIRO; DOLZ, 2005). Ou seja, na dificuldade que o professor ainda possui em articular as três dimensões acima elencadas.

Por essa razão, reiteramos aqui a nossa posição teórica de compreender o objeto ensinado em sala de aula a partir da análise do trabalho do professor, cujo objeto "são os processos psicológicos dos alunos; [...] os modos de pensar, de falar e de agir que ele deverá transformar em função das finalidades definidas pelo sistema escolar" (SCHNEUWLY, 2009, p. 30). Esse objeto diferencia-se do objeto de ensino, que, segundo Schneuwly (2009, p. 33), deve ser compreendido como o "o resultado - de certa maneira virtual, em constante mutação - do trabalho do professor em função do agir deste sobre as capacidades dos alunos; estes últimos continuam sendo o objeto real e, portanto, inatingível do trabalho docente $[. .$.$] ".$

O trabalho de mediação do professor na sala de aula implica, portanto, um processo de semiotização do objeto de ensino por meio de diferentes ferramentas de ensino, as quais incluem não só os artefatos produzidos exclusivamente para a atividade de ensino (livro didático, obras complementares, apostilas, mídias digitais etc.), como também os de natureza tecnológica (internet, aparelhos de DVD, televisão, computador, projetor multimídia) ou simbólica (jornais, revistas, etc.) produzidos pela sociedade; ou, ainda, os provenientes de fonte natural (água, folhas, pedras, etc.) que, embora não se destinem à atividade de ensino, podem ser direcionados para tal.

Persp. Online: hum \& sociais aplicada., Campos dos Goytacazes, 28 (10)80-97- 2020 
O objeto de ensino de que tratamos aqui é o gênero, concebido oficialmente como tal desde a publicação dos Parâmetros Curriculares de Língua Portuguesa (PCN), no final do século XX. O objetivo dos PNC era o de desestabilizar práticas de ensino de língua pautadas exclusivamente na norma gramatical e que até então eram vistas como problemáticas. O caminho, portanto, era o de viabilizar o envolvimento do aluno com a diversidade de gêneros que circulavam nos mais diferentes espaços sociais, permitindo não só a identificação dos elementos linguísticos constitutivos do texto, mas também compreender como tais elementos são organizados em função dos propósitos comunicativos pretendidos no ato da interação.

Todavia, cerca de vinte anos se passaram e a problemática de ensino de gêneros na escola ainda persiste, como revela o estudo de Lima (2016). Segundo o autor, questões acerca do que e como ensinar gêneros ainda inquietam muitos docentes, que têm buscado em cursos de formação continuada e eventos científicos subsídios teórico-metodológicos que os auxiliem a lidar com esse "novo" objeto na sala de aula. Ainda segundo o pesquisador, "há uma forte tendência à teorização e à exploração sistemática de algumas dimensões constitutivas do gênero (composição, estilo, conteúdo temático) no processo de decomposição do objeto de ensino" (LIMA, 2016, p. 253).

Assim, com o objetivo de compreender os motivos e as razões acerca do agir didático do professor de língua portuguesa em relação ao ensino de gêneros, recorremos ao diálogo com as disciplinas do trabalho, em especial, os estudos de Amigues (2004), Clot (2007), Machado (2010) e Bronckart (2006). Este último entende que "a atividade de ensino tem sido considerada como um verdadeiro trabalho, cujas características passaram a ser objeto de reflexões de debates e de pesquisas de caráter didático e/ou científico (BRONCKART, 2006, p. 203).

Sob esse viés, trabalho do professor não se restringe apenas ao momento da sala de aula, onde ele explica os conteúdos e realiza atividades, há todo um processo anterior que orienta essa prática e afeta o planejamento e a realização da aula, o qual denominamos "trabalho prescrito" (BRONCKART, 2006). Esse trabalho seria, portanto, aquele que antecede a aula, como, por exemplo, quando o professor planeja sua aula e tem por base um documento oficial que determina o que deve ser ministrado para aquela turma, naquele momento do ano letivo, com conteúdos e habilidades previamente definidos. Os livros didáticos e os documentos oficiais são constitutivos desse trabalho prescrito.

Já o trabalho realizado é aquilo que efetivamente o professor faz na sala de aula. Sabemos, entretanto, que o docente pode elaborar um planejamento de aula (o trabalho prescrito) e não conseguir pôr em prática aquilo que foi planejado, acarretando, muitas vezes, em situações e resultados diferentes do esperado. É nesse momento que entra em cena o "trabalho real" (CLOT, 2007), que se situa justamente entre o que é prescrito e o que é realizado. Trata-se de um trabalho invisível e invisibilizado por muitos pesquisadores, pois envolve processos psíquicos internos do trabalhador, num movimento de inquietude, de conflitos, de indefinição, de redescobrir, de ajustar e de reformular algumas estratégias para atingir objetivos específicos. No caso do professor, os objetivos de ensino e de aprendizagem. Assim, no âmbito dos estudos que versam sobre a relação trabalho e linguagem na atividade docente, cumpre observar até que ponto os elementos acima referidos são reconfigurados nos textos produzidos pelos professores como possibilidades/impedimentos para o seu agir (AMIGUES, 2004).

Persp. Online: hum \& sociais aplicada., Campos dos Goytacazes, 28 (10)80-97- 2020 
Ademais, diferentemente do que acontece, por exemplo, na atividade industrial, em que há uma maior objetividade em relação ao que deve ser feito para alcançar a produtividade, no trabalho do professor, isso se torna um pouco mais complexo no sentido de que esse trabalho "inscreve-se em uma organização com prescrições vagas, que levam os professores a redefinir para si mesmos as tarefas que lhes são prescritas, de modo a definir as tarefas que eles vão, por sua vez, prescrever aos alunos" (AMIGUES, 2004, p. 42).

Em síntese, podemos afirmar que o trabalho do professor está imerso em uma rede histórico-discursiva mais ampla, composta não só pela instituição escola, mas por um conjunto macro de prescrições e políticas públicas ou normas inerentes ao sistema educacional que, de alguma forma, regulam, ideologicamente, o seu agir didático na sala de aula. Sendo assim, o nosso objetivo neste artigo é o de desvelar um pouco os bastidores do trabalho docente, investigado, a partir das verbalizações dos próprios professores, como eles ressignificam o seu agir didático com gêneros nas aulas de língua portuguesa.

\section{METODOLOGIA}

A pesquisa desenvolvida segue abordagem qualitativa (LÜDKE; ANDRÉ, 2012), uma vez que a nossa preocupação reside na apreensão e na interpretação dos significados sobre o ensino de gênero sob a ótica do próprio professor. A coleta de dados ocorreu por meio de uma pesquisa de campo. Segundo Beaud e Weber (2007, p. 15),

Fazer pesquisa de campo é ter vontade de se agarrar aos fatos, de discutir com os pesquisados, de compreender melhor os indivíduos e os processos sociais. Sem essa sede de descobrir, sem essa vontade de saber, quase que destrinchar, o campo tornar-se uma formalidade, um exercício escolar, chato, sem interesse.

Os dados foram obtidos através da colaboração de duas professoras, cujo exercício do trabalho ocorre em turmas do ensino fundamental de duas escolas de dois municípios do Agreste Meridional de Pernambuco, a saber: Caetés e Garanhuns. Atendendo a questões éticas, a professora do município de Garanhuns será tratada aqui como PL1 e a de Caetés como PL2.

A geração de dados ocorreu, inicialmente, por meio de observações de duas sequências de ensino (SE) com gêneros, uma de cada professora colaboradora. A SE de PL1 contemplou os gêneros Cartum e Charge, já a SE de PL2 foi realizada com o gênero autobiografia. As aulas foram devidamente registradas em áudio e vídeo, com o auxílio de uma mini filmadora digital e um aparelho de celular. Essa coleta ocorreu entre o período de maio a junho de 2019 (coleta realizada na fase anterior desta pesquisa), sendo observadas uma SE de 5 aulas de PL1 e outra, com 6 aulas, de PL2, conforme ilustram os quadros a seguir:

Quadro 1: síntese da SE de PL1: gêneros charge e cartum. Fonte: Elaboração própria.

\begin{tabular}{|c|c|}
\hline AULA & SÍNTESE \\
\hline 1 & $\begin{array}{l}\text { - Apresentação do gênero Cartum e Charge aos alunos por meio de imagens de } \\
\text { Cartum e Charge e uma proposta de exercício referente a esses gêneros. }\end{array}$ \\
\hline 2 & $\begin{array}{l}\text { - Explicação sobre os suportes dos gêneros cartum e charge e quais aspectos eles } \\
\text { carregam, que, no caso, é a criticidade e o humor. }\end{array}$ \\
\hline 3 a 5 & $\begin{array}{l}\text { - resolução de perguntas referentes às imagens que foram vistas na aula } 1 . \\
\text { Socialização dessa atividade }\end{array}$ \\
\hline
\end{tabular}

Persp. Online: hum \& sociais aplicada., Campos dos Goytacazes, 28 (10)80-97- 2020 
- $\mathrm{Na}$ aula 5, foi feita a resolução do simulado Aprova Brasil (programa de desenvolvimento de proficiência em leitura adotado pela prefeitura local) sobre esses gêneros estudados.

Quadro 2: síntese da SE de PL2: gênero autobiografia. Fonte: Elaboração própria.

\begin{tabular}{|c|c|}
\hline AULA & SÍNTESE \\
\hline 1 & $\begin{array}{l}\text { - Apresentação do gênero autobiografia, focalizando a sua estrutura. } \\
\text { - Anotação de pontos importantes no slide sobre a autobiografia. }\end{array}$ \\
\hline 2 e 3 & $\begin{array}{l}\text { - análise de uma autobiografia. } \\
\text { - Como "para casa", a professora solicita que os alunos façam uma pesquisa de } \\
\text { autobiografia de famosos. }\end{array}$ \\
\hline 4 & - Explora a importância do gênero autobiografia. \\
\hline 5 e 6 & $\begin{array}{l}\text { - os alunos produzem o gênero autobiografia e socializam suas produções para o } \\
\text { grande grupo. }\end{array}$ \\
\hline
\end{tabular}

Considerando os objetivos propostos para este estudo, selecionamos trechos das SE de ambas as professoras para a etapa seguinte da pesquisa, a qual consistiu na realização do procedimento de autoconfrontação simples (ACS) com as professoras colaboradoras. De acordo com Clot (2007, p. 135), "a autoconfrontação clássica é na verdade orientada por um pesquisador, seja psicólogo ou não. Ora, trata-se de uma atividade em si em que o trabalhador descreve sua situação de trabalho para o pesquisador" (grifos do autor). Na ACS, as verbalizações são vistas como necessárias para trazer "à luz as realidades do trabalho" (CLOT, 2007, p. 135). Em se tratando do trabalho docente, Santos (2017, p. 146) afirma que os professores "ao se defrontarem com sua própria imagem, tornam-se outro para si mesmos e, assim, constroem ressignificações, ou seja, novos sentidos e significados, sobre sua própria prática”.

Ainda segundo Clot (2007), a análise do trabalho é inseparável da transformação, ou seja, não se pode pensar sobre a análise do trabalho sem pensar na sua transformação. Partindo dessa premissa, nessa fase do estudo, o foco recaiu nas verbalizações das professoras, de modo a compreender melhor as escolhas feitas por elas ao trabalharem com os gêneros na sala de aula. Também foi o momento oportuno para fazê-las repensar sobre o seu próprio agir didático com gêneros ao se colocarem como analistas do próprio trabalho.

$\mathrm{Na}$ fase da ACS, disponibilizamos um notebook para que as professoras assistissem aos trechos de suas aulas. Utilizamos também uma câmera filmadora para registrar as reações, os comentários e as reflexões feitas pelas docentes. Com PL2, a ACS foi dividida em dois momentos, totalizando 2 horas e 30 minutos. Já com PL1, a ACS ocorreu em um único momento e teve duração de 1 hora. 


\section{RESULTADOS E DISCUSSÃO}

A seguir, apresentados dois quadros com uma síntese das ressignificações do agir didático com gênero de ambas as professoras. A análise das verbalizações das professoras nas das sessões de ACS possibilitou a geração de 05 categorias, a saber: (1) ressignificações atribuídas às necessidades de ensino da professora; (2) ressignificações atribuidas aos modos de organização de trabalho com o gênero na sala de aula; (3) ressignificações atribuídas à relação do gênero com os usos da língua fora da escola; (4) ressignificações atribuidas à necessidade de contemplar as prescrições oficiais e (5) ressignificações atribuidas às potencialidades do gênero no ensino de língua. Ressaltamos que todas as transcrições foram feitas de forma literal.

Quadro 3 - Síntese da ACS de PL1. Fonte: elaborado com base em Santos (2017).

\begin{tabular}{|c|c|c|}
\hline $\begin{array}{c}\text { MOMENTO } \\
\text { DA AULA }\end{array}$ & $\begin{array}{c}\text { AS INTERVENÇÕES DOS } \\
\text { PESQUISADORES E AS RESPOSTAS } \\
\text { DE PL1 }\end{array}$ & RESSIGNIFICAÇÃO \\
\hline \begin{tabular}{|l}
\multicolumn{2}{l}{ Professora } \\
escreve no \\
quadro uma \\
atividade sobre \\
os gêneros \\
estudados.
\end{tabular} & $\begin{array}{l}\text { Pesquisador: nessa parte aqui, a gente foca } \\
\text { mais na questão da professora escolher levar } \\
\text { o conteúdo para escrever no quadro. Qual foi } \\
\text { o motivo de levar o conteúdo para escrever } \\
\text { no quadro? } \\
\text { PL1: acho que a questão da escrita, deles } \\
\text { poderem aprender com a própria escrita } \\
\text { deles, porque na escola pública, ou na escola } \\
\text { de educação básica, ainda é muito } \\
\text { considerado a escrita, até pelo fato deles não } \\
\text { estarem escrevendo com frequência } \\
\text { Pesquisador: então é um instrumento } \\
\text { necessário? } \\
\text { PL1: sim }\end{array}$ & $\begin{array}{c}\text { atribuída à } \\
\text { necessidade de ensino } \\
\text { da professora }\end{array}$ \\
\hline $\begin{array}{l}\text { A professora } \\
\text { utiliza o slide } \\
\text { para apresentar } \\
\text { exemplos de } \\
\text { gêneros, suas } \\
\text { características, } \\
\text { sua função. }\end{array}$ & $\begin{array}{l}\text { Pesquisador: aqui, professora, nesse } \\
\text { momento, a gente se atenta ao jeito que a } \\
\text { professora levou o gênero. A professora } \\
\text { levou o gênero por meio de slides, aí a gente } \\
\text { gostaria de saber por que a escolha do slide } \\
\text { aqui foi importante pra levar o gênero por } \\
\text { meio de slide com imagem? } \\
\text { PL1: por questão de visualização, questão } \\
\text { do slide chamar muita atenção por } \\
\text { conseguir deixar com que a aula fique mais } \\
\text { rápida, também não desperdiçar material, } \\
\text { tipo xerox. Às vezes, eu passo o material na } \\
\text { xerox e recolho dos alunos tudo pra não } \\
\text { desperdiçar. E o slide ele fica mais fácil } \\
\text { utilizar na conversação. Eles entendem } \\
\text { bastante essa charge, porque era uma coisa }\end{array}$ & $\begin{array}{c}\text { atribuída à } \\
\text { necessidade de ensino } \\
\text { da professora }\end{array}$ \\
\hline
\end{tabular}

Persp. Online: hum \& sociais aplicada., Campos dos Goytacazes, 28 (10)80-97- 2020 seer.perspectivasonline.com.br 


\begin{tabular}{|c|c|c|}
\hline & $\begin{array}{l}\text { tranquila também a observação da } \\
\text { interpretação da charge como um todo, não } \\
\text { tinha nada escrito, mas eles conseguiram } \\
\text { entender. Então, acho que o slide é uma } \\
\text { ferramenta muito boa em sala de aula e } \\
\text { além de que ano que vem também eu já } \\
\text { utilizo esse mesmo material só faço as } \\
\text { adequações necessárias, entendeu? Então é } \\
\text { um material muito bom para a sala de aula, } \\
\text { um recurso seu. }\end{array}$ & \\
\hline $\begin{array}{lr}\text { A professora } \\
\text { escreve no } \\
\text { quadro } & \text { uma } \\
\text { atividade } & \\
\text { produzida } & \text { por } \\
\text { ela mesma. } & \end{array}$ & $\begin{array}{l}\text { Pesquisador: situando mais assim a questão } \\
\text { de atividades, no caso a atividade autoral da } \\
\text { própria professora que fez a atividade, aí a } \\
\text { gente gostaria de saber mesmo o porquê de } \\
\text { levar atividades autorais pra os alunos. } \\
\text { PL1: é justamente pelo fato de eu saber, eu } \\
\text { acho que eu consigo entender a dificuldade } \\
\text { que ele tem (), aí eu percebo muito isso, às } \\
\text { vezes a atividade não é a realidade do seu } \\
\text { aluno. Às vezes, quando você consegue } \\
\text { produzir, ele quer. Âs vezes, é um assunto } \\
\text { bem simples como, por exemplo, eu gosto } \\
\text { muito assim de um assunto, eu fico uma } \\
\text { monte de tempo explicando verbo, às vezes } \\
\text { fica até repetitivo, e eu faço questão de que } \\
\text { eles façam aquela conjugação porque eles } \\
\text { não sabem e se você pegar um monte de aula } \\
\text { com a aquela conjugação, você vai dizer que } \\
\text { é uma coisa ultrapassada, mas não é, é } \\
\text { preciso fazer, então é justamente saber o que } \\
\text { o aluno tem que não aprendeu. }\end{array}$ & $\begin{array}{c}\text { atribuída à } \\
\text { necessidade de ensino } \\
\text { da professora }\end{array}$ \\
\hline $\begin{array}{l}\text { No slide, a } \\
\text { professora } \\
\text { mostra aos } \\
\text { alunos as } \\
\text { características } \\
\text { da Charge. }\end{array}$ & $\begin{array}{l}\text { Pesquisador: Por que você iniciou o trabalho } \\
\text { com o gênero apresentando-o dessa forma? } \\
\text { PL1: como eu já disse, o slide ele acaba } \\
\text { mostrando melhor, charge é uma coisa que } \\
\text { eles já conhecem, eles já viram as situações, } \\
\text { são coisas que estão inseridas } \\
\text { cotidianamente, então eles já sabem. Então, } \\
\text { dessa forma, é como se fosse um espiral, a } \\
\text { gente tá voltando os conteúdos. }\end{array}$ & $\begin{array}{c}\text { atribuída à } \\
\text { necessidade de ensino } \\
\text { da professora }\end{array}$ \\
\hline $\begin{array}{l}\text { A professora } \\
\text { explica a dos } \\
\text { relação der dum } \\
\text { gêneros cartum } \\
\text { e charge com o } \\
\text { contexto social. } \\
\text { A partir dessa } \\
\text { observação, }\end{array}$ & $\begin{array}{l}\text { Pesquisador: a gente percebe aqui, também, } \\
\text { professora, a função social do gênero. Você } \\
\text { levou em conta o contexto social. Por que é } \\
\text { interessante levar em conta a função social? } \\
\text { PL1: porque eu costumo dizer, assim, que, } \\
\text { de alguma forma, aluno não está pra escola, } \\
\text { ele tem que saber que aquilo dali vai }\end{array}$ & $\begin{array}{l}\text { atribuida à relação do } \\
\text { gênero com os usos da } \\
\text { língua fora da escola. }\end{array}$ \\
\hline
\end{tabular}

Persp. Online: hum \& sociais aplicada., Campos dos Goytacazes, 28 (10)80-97- 2020 seer.perspectivasonline.com.br 


\begin{tabular}{|c|c|c|}
\hline $\begin{array}{l}\text { perguntamos a } \\
\text { importância de } \\
\text { se trabalhar } \\
\text { também com o } \\
\text { contexto social. }\end{array}$ & $\begin{array}{l}\text { ultrapassar o muro. Então, ele deve chegar e } \\
\text { explicar, por exemplo, uma coisa que eu } \\
\text { gosto de fazer nas minhas aulas, eu não sei } \\
\text { se estou errada, mas, por exemplo, as } \\
\text { funções, os adjuntos, por exemplo, quando } \\
\text { eles saírem da escola, não vão utilizar, mas } \\
\text { quando ele sair da escola, ele vai utilizar } \\
\text { uma charge, então pensando nisso, pensando } \\
\text { no depois, como ele vai fazer uma leitura, } \\
\text { uma interpretação de tudo, então, eu acho } \\
\text { que esses trabalhos, eles prezam pela vida } \\
\text { do aluno lá fora, isso que eu gosto, já esses } \\
\text { outros assuntos que são mais que eles } \\
\text { esquecem rapidamente, eu, algumas vezes, } \\
\text { acabo dando aquela fujidinha, não por } \\
\text { questão de não achar que não é importante, } \\
\text { mas por achar que tem outros que são bem } \\
\text { mais importantes. } \\
\text { Pesquisador: para a vida do aluno? } \\
\text { PLl: isso }\end{array}$ & \\
\hline $\begin{array}{l}\text { A professora } \\
\text { entrega várias } \\
\text { charges } \\
\text { impressas e } \\
\text { pede para os } \\
\text { alunos } \\
\text { responderem } \\
\text { algumas } \\
\text { questões e, } \\
\text { depois, } \\
\text { socializarem } \\
\text { suas respostas. }\end{array}$ & $\begin{array}{l}\text { PL1: essa foi a socialização, não foi? } \\
\text { Pesquisador: sim } \\
\text { PL1: essa foi a parte que eu dei várias } \\
\text { charges diferentes e pedi para eles } \\
\text { responderem a algumas questões e, na hora } \\
\text { da socialização, eles têm essa dificuldadee, } \\
\text { porque eles se sentem inseguros em relação } \\
\text { a isso, dessa divisão, principalmente quando } \\
\text { precisa expor as ideias. Então, eu chamei } \\
\text { eles lá na frente pra dizer o que } \\
\text { interpretaram. Também é interessante essa } \\
\text { atividade porque é charges diferentes e aí } \\
\text { eles tinham que apresentar a que tinha } \\
\text { ficado, e às vezes você entende o que tinha } \\
\text { na charge mas eu não vi, então, eu não vou } \\
\text { entender. }\end{array}$ & $\begin{array}{c}\text { atribuída à } \\
\text { necessidade de ensino } \\
\text { da professora }\end{array}$ \\
\hline $\begin{array}{l}\text { A professora } \\
\text { entrega várias } \\
\text { charges } \\
\text { impressas e } \\
\text { pede para os } \\
\text { alunos } \\
\text { respondam } \\
\text { algumas } \\
\text { questões e, } \\
\text { depois, }\end{array}$ & $\begin{array}{l}\text { Pesquisador: então, qual a importância que a } \\
\text { senhora vê dessa atividade? De entregar, } \\
\text { deles socializarem com os outros? } \\
\text { PL1: acho que, primeiramente, por ter sido } \\
\text { momentos diferentes, como cada um pôde } \\
\text { observar. E, às vezes, dizia assim: eita, qual } \\
\text { foi a tua? Ter a curiosidade de saber qual foi } \\
\text { a charge do outro e também deles verem } \\
\text { diferentes pontos de vistas e também }\end{array}$ & $\begin{array}{c}\text { atribuída à } \\
\text { necessidade de ensino } \\
\text { da professora }\end{array}$ \\
\hline
\end{tabular}

Persp. Online: hum \& sociais aplicada., Campos dos Goytacazes, 28 (10)80-97- 2020 seer.perspectivasonline.com.br 


\begin{tabular}{|c|c|c|}
\hline $\begin{array}{l}\text { socializarem } \\
\text { suas respostas. }\end{array}$ & $\begin{array}{l}\text { perceber a questão da intertextualidade, } \\
\text { costumo dizer sempre que, às vezes, você } \\
\text { entende, mas eu não entendi porque eu não } \\
\text { vi. Então, precisa estar ligado com aquele } \\
\text { momento. Então, é o descobrir, é essa } \\
\text { memória que a gente esquece rapidamente. }\end{array}$ & \\
\hline $\begin{array}{l}\text { (Retomamos as } \\
\text { ações } \\
\text { realizadas pela } \\
\text { professora e } \\
\text { focamos no } \\
\text { motivo pelo } \\
\text { qual foi } \\
\text { realizada dessa } \\
\text { forma a } \\
\text { estruturação da } \\
\text { sequência) }\end{array}$ & $\begin{array}{l}\text { Pesquisador: professora, só mais uma } \\
\text { perguntinha: o que levou a professora a } \\
\text { organizar essas atividades assim dessa } \\
\text { forma? A professora apresentou o gênero, aí } \\
\text { depois pediu uma atividade sobre, depois } \\
\text { levou o slide. Dentro do slide, tinha as } \\
\text { imagens, a estrutura, para, depois, vim } \\
\text { chegar realmente na questão deles } \\
\text { responderem o simulado. O que levou a } \\
\text { professora a organizar essas atividades } \\
\text { assim, nesse estilo? } \\
\text { PL1: primeiramente, a apresentação visual } \\
\text { da charge, até porque que eles já conhecem, } \\
\text { então, apresentar a charge visual é trazer à } \\
\text { sua memória. Tipo assim, nós vamos agora } \\
\text { estudar a charge, e a gente vê, sabe o que é, } \\
\text { e depois ir refrescando o que ela é de fato, } \\
\text { quais são os objetivos dela. Eu acho que } \\
\text { iniciar com a charge é bem isso. E, por } \\
\text { último, a construção do exercício, a gente já } \\
\text { viu, a gente já lembrou, já sabe qual é a } \\
\text { estrutura, então, é praticar a interpretação em } \\
\text { si porque a charge também é uma questão } \\
\text { interpretativa. }\end{array}$ & $\begin{array}{l}\text { atribuída aos modos de } \\
\text { organização de } \\
\text { trabalho com o gênero } \\
\text { na sala de aula. }\end{array}$ \\
\hline $\begin{array}{l}\text { Neste } \\
\text { momento, a } \\
\text { professora está } \\
\text { utilizando o } \\
\text { livro didático, o } \\
\text { que ocorreu em } \\
\text { três aulas da } \\
\text { sequência. }\end{array}$ & $\begin{array}{l}\text { Pesquisador: a senhora utilizou o livro } \\
\text { didático com os simulados, não foi? Então, } \\
\text { por que você trabalhou, nesse momento, } \\
\text { com o livro didático? } \\
\text { PL1: porque, veja só, o livro ele é sequência, } \\
\text { uma sequência de gêneros e era justamente a } \\
\text { semana que iria ter a charge ou Cartum, um } \\
\text { dos dois, mas eu quis colocar os dois perto } \\
\text { um do outro porque eu precisava explicar a } \\
\text { diferença dos gêneros. Um depende do } \\
\text { contexto histórico e o outro, não, o outro } \\
\text { serve para qualquer época, e vai fazer essa } \\
\text { diferença entre os dois, justamente pela } \\
\text { questão do momento. Ai na hora a gente fez } \\
\text { a leitura para falar: essa aqui é a charge, } \\
\text { esse aqui é o Cartum. Para eles } \\
\text { conseguirem perceber a diferença entre os } \\
\text { dois. E o livro didático, como era uma }\end{array}$ & $\begin{array}{c}\text { atribuida à } \\
\text { necessidade de ensino } \\
\text { da professora }\end{array}$ \\
\hline
\end{tabular}

Persp. Online: hum \& sociais aplicada., Campos dos Goytacazes, 28 (10)80-97- 2020 seer.perspectivasonline.com.br 


\begin{tabular}{|l|l|c|}
\hline & $\begin{array}{l}\text { Sequência, lá tinha uma atividade que já } \\
\text { vinha pronta e tudo, então, o fim para essa } \\
\text { aula era justamente a aula com o livro } \\
\text { didático. Eles precisavam responder aquela } \\
\text { lição. }\end{array}$ & \\
\hline $\begin{array}{l}\text { A professora } \\
\text { apresenta no } \\
\text { slide diferentes } \\
\text { exemplos dos } \\
\text { gêneros charge } \\
\text { e cartum. }\end{array}$ & $\begin{array}{l}\text { você levou muitos exemplares dos gêneros, } \\
\text { tanto do Cartum quanto da charge, qual a } \\
\text { importância de apresentar esses exemplos }\end{array}$ & $\begin{array}{r}\text { necessidade de ensino } \\
\text { da professora }\end{array}$ \\
& $\begin{array}{l}\text { PL1: a questão visual, a questão dele poder } \\
\text { observar e interpretar, também fazer essa } \\
\text { leitura visual não era a leitura de um texto } \\
\text { qualquer, era uma coisa de ir observando e } \\
\text { sempre fazendo a leitura de um cada um, do } \\
\text { conhecimento que ele tem. }\end{array}$ & \\
\hline
\end{tabular}

Na geração de dados da ACS de PL1, foram encontradas três categorias. A primeira, a de (1) ressignificações atribuidas às necessidades de ensino da professora, com 06 ocorrências, contemplava algumas questões ligadas: a) à importância do gênero no aprendizado da escrita ("acho que a questão da escrita [...]"); b) à necessidade de utilização de recursos didáticos específicos como um suporte a mais para a abordagem do gênero ("por questão de visualização, slide chamar muita atenção [...]" / [...] "o slide, ele acaba mostrando melhor, charge é uma coisa que eles já conhecem [...]"); e c) à realização de atividades para diagnosticar as dificuldades do aluno em relação ao gênero ("eu acho que eu consigo entender a dificuldade que ele tem [..]" / "para eles [os alunos] conseguirem perceber a diferença entre os dois [charge e cartum]")

As outras duas, (2) ressignificações atribuídas aos modos de organização de trabalho com o gênero na sala de aula; (3) ressignificações atribuídas à relação do gênero com os usos da língua fora da escola tiveram apenas 01 ocorrência cada. No que concerne à categoria (2), ela estava relacionada ao planejamento da sequência com o gênero, às etapas e atividades previstas e aos objetivos de ensino e de aprendizagem (" [...] nós vamos agora estudar a charge, e a gente vê, sabe o que é, e depois ir refrescando o que ela é de fato, quais são os objetivos dela. Eu acho que iniciar com a charge é bem isso [..]” ). Já a (3) revela a preocupação de PL1 com a apropriação do gênero como ferramenta para agir, por meio da linguagem, em situações fora do contexto escolar ("[...] ele tem que saber que aquilo dali vai ultrapassar o muro [...]"). Vejamos agora o quadro síntese da ACS de PL2:

Quadro 4 - Síntese da ACS PL2, Fonte: elaborado com base em Santos (2017).

\begin{tabular}{|l|c|c|}
\hline $\begin{array}{l}\text { MOMENTO } \\
\text { DA AULA }\end{array}$ & $\begin{array}{c}\text { AS INTERVENÇÕES DOS } \\
\text { PESQUISADORES E AS RESPOSTAS DE }\end{array}$ & RESSIGNIFICAÇÃO \\
\hline $\begin{array}{l}\text { P professora } \\
\text { fala sobre a } \\
\text { possibilidade } \\
\text { de publicação }\end{array}$ & $\begin{array}{l}\text { PL2: Quanto à publicação, a gente ainda está } \\
\text { com um impasse, porque alguns pais, eu pedi } \\
\text { para que a coordenação entrasse em contato } \\
\text { com os pais para que eles liberassem. Alguns }\end{array}$ & $\begin{array}{l}\text { atribuída à relação do } \\
\text { lingua for ora da escola. }\end{array}$ \\
\hline
\end{tabular}

Persp. Online: hum \& sociais aplicada., Campos dos Goytacazes, 28 (10)80-97- 2020 seer.perspectivasonline.com.br 

das
autobiografias
em um Blog. deles ficam meio receosos, mas não vai afetar em nada diretamente a pessoa. Eu também fiquei ausente por três meses. Na volta, tentei entrar em contato com os pais através de comunicados, alguns aceitaram, eu diria, a maioria aceitou, e uma minoria não aceitou e isso gerou um impasse. Esse impasse é devido a questão deles acharem que vai expor o filho, mas assim, a gente pode fazer um corte, aí a gente chegou numa ideia, de que queria criar pseudônimos, a gente publica, porém com outros nomes, aí assim surgiram vários nomes, uns até engraçados. Eu vou ver primeiro se dá certo, porque, com esses novos nomes, pode ser que os pais criem menos impasses. Como eu fiz nessa sala, também teve as outras e eu não vou deixar de publicar também. São mais de 90 textos. E tem realmente algumas coisas que são de família mesmo, eu acho que não é interessante fazer esse tipo de publicação, tem coisas que não é legal, aí eu achei interessante para quando eles forem digitar, eles, não tirar, mas amenizar ou colocar com outras palavras, porque são questões bem pessoais e fica muito exposto.

Pesquisador: Por quê? e qual a importância dessa publicação?

PL2: É que, assim, eu ainda não estou tão por dentro da nova BNCC, a gente já teve algumas formações, a gente já tá trabalhando, porém foi assim, um montante de coisas novas que foi jogado pra gente. É o que acontece infelizmente. E, assim, não teve uma formação necessária, foi apenas uma formação e nem foi direcionada para áreas específicas, foi de uma forma geral, e isso fica para o professor estudar, pesquisar. E agora os gêneros estão sendo atrelados aquelas questões de publicações mesmo, atrelados a mídia, aos podcasts. É a semiótica e tudo isso envolve a publicação, é que quando você trabalha o gênero, você tem que ver o que você pode publicar, se você pode fazer essa publicação, lógico que para enriquecimento, pra publicação, pra explanação, pra conhecimento, pra tudo! pra ir além da escola. Ai a gente tem que atrelar a autobiografia com a publicação, eu achei muito interessante para que outras escolas, outros 


\begin{tabular}{|c|c|c|}
\hline & $\begin{array}{l}\text { grupos, outras pessoas possam copiar, possam } \\
\text { ver, possam melhorar. }\end{array}$ & \\
\hline $\begin{array}{l}\text { Início da } \\
\text { sequência. A } \\
\text { professora } \\
\text { fala um pouco } \\
\text { sobre as } \\
\text { características } \\
\text { do gênero. }\end{array}$ & $\begin{array}{l}\text { Pesquisador: Por que a professora escolheu o } \\
\text { gênero autobiografia e não outro? } \\
\text { PL2: Primeiro, porque está no programa, o } \\
\text { programa ele é aberto, flexivel, mas eu acho } \\
\text { interessante pelo conhecimento do aluno, é } \\
\text { muito importante conhecer seu aluno, dei mais } \\
\text { valor a esse gênero, porque quando você } \\
\text { conhece seu aluno, você pode até melhorar seu } \\
\text { trabalho. }\end{array}$ & $\begin{array}{c}\text { atribuída à } \\
\text { necessidade de } \\
\text { contemplar as } \\
\text { prescrições oficiais e } \\
\text { às necessidades de } \\
\text { ensino da professora }\end{array}$ \\
\hline $\begin{array}{l}\text { A professora } \\
\text { apresenta aos } \\
\text { alunos as } \\
\text { características } \\
\text { do gênero. }\end{array}$ & $\begin{array}{l}\text { Pesquisador: Se a professora, como já teve essa } \\
\text { experiência de agora, se for em outra turma, a } \\
\text { professora já pode repensar algo? } \\
\text { PL2: posso repensar, já posso até ampliar, } \\
\text { posso não pedir mais produção, posso pedir } \\
\text { análise, posso focar numa situação pessoal, vai } \\
\text { se juntar com a questão dos pseudônimos. } \\
\text { Houve um caso na escola de suicídio e ela tinha } \\
\text { depressão, a gente poderia fazer análises de } \\
\text { outras autobiografias direcionadas a questão } \\
\text { de tristeza, de depressão, suicídio, poderia } \\
\text { fazer um projeto. Então, assim, a aula, o } \\
\text { desenrolar da situação vai ser uma questão de } \\
\text { momento, a aula é isso, essa dinâmica da vida, } \\
\text { do cotidiano, você imagina, pensa, planeja, mas } \\
\text { amanhã você já pode ter outra ideia, já pode ter } \\
\text { outro foco, aí já pode fazer um outro } \\
\text { desenvolvimento, ela não fica, ela não morre, a } \\
\text { aula, o assunto, o gênero, ele caminha, ele tem } \\
\text { uma vida, ele tem um milhão de... eu diria de } \\
\text { dedos, de mãos, e que você pode dar uma vida } \\
\text { a isso, sabe? Ele não é só isso. } \\
\text { Pesquisador: Ele não acaba na sala? } \\
\text { PL2: Não, de forma nenhuma, ele continua, pra } \\
\text { outras salas, outras turmas, no outro ano você } \\
\text { já pode trabalhar de outra forma, depende da } \\
\text { necessidade, do público, do que você quer } \\
\text { atingir, assim, é muito dinâmico, o gênero é } \\
\text { muito dinâmico, o gênero é extremamente } \\
\text { dinâmico, não sei onde vai parar esse } \\
\text { dinamismo, e dá muito abertura para novas } \\
\text { ideias, é muito bom trabalhar com gêneros, } \\
\text { porque floresce, a cada dia você tem uma ideia } \\
\text { diferente pra trabalhar com gêneros. Aí, eu } \\
\text { escolhi contos de assombração, a gente iniciou }\end{array}$ & $\begin{array}{c}\text { atribuída às } \\
\text { potencialidades do } \\
\text { gênero no ensino de } \\
\text { língua. }\end{array}$ \\
\hline
\end{tabular}

Persp. Online: hum \& sociais aplicada., Campos dos Goytacazes, 28 (10)80-97- 2020 seer.perspectivasonline.com.br 


\begin{tabular}{|c|c|c|}
\hline & $\begin{array}{l}\text { na semana do Halloween, nas aulas de } \\
\text { português, aí eu aproveitei no próprio livro } \\
\text { didático, aproveitei que lá traz alguns de } \\
\text { suspense, "Os olhos que comem carne", e isso } \\
\text { dá margem pra outra coisa, e você já viaja, a } \\
\text { gente fez os trabalhos numa sala escura. Assim, } \\
\text { aí você volta, eu tenho uma prática de muitos } \\
\text { anos só de trabalhar a análise linguística com o } \\
\text { texto mesmo, como pretexto, só respondendo } \\
\text { questões, aí quando a gente faz inserindo na } \\
\text { modernidade, né? A gente vai se inserindo na } \\
\text { modernidade, aí vai vendo como é dinâmico, aí } \\
\text { você começa a trabalhar com gêneros, aí você } \\
\text { vê como ele é dinâmico, você faz uma coisa, } \\
\text { você faz outra, você produz, é tanta ideia, é tão } \\
\text { grande, assim, o gênero acho que não tem fim, } \\
e ́ \text { quase que infinito, porque eu tenho uma } \\
\text { ideia, você tem outra, eles tem outra, amanhã } \\
\text { eu já apareço com outra, né? e melhora muito } \\
\text { o trabalho, de verdade, porque nessas aulas de } \\
\text { hoje a gente tem que surpreender, se você ficar } \\
\text { com a mesmice a aula não flui, e o gênero dá } \\
\text { esse suporte pra gente. Ah, mas eles já estão } \\
\text { tão conectados com a internet! sim, mas eles } \\
\text { não tão com aquilo que você está planejando } \\
\text { muitas vezes, então, é surpresa aquela } \\
\text { produção, aquele trabalho, aquela dinâmica, é } \\
\text { pra ser surpresa, então envolve. }\end{array}$ & \\
\hline $\begin{array}{l}\text { A professora } \\
\text { utiliza o slide } \\
\text { para mostrar a } \\
\text { estrutura do } \\
\text { gênero. } \\
\text { ((nesse } \\
\text { momento, } \\
\text { retomamos as } \\
\text { atividades } \\
\text { que a } \\
\text { professora } \\
\text { realizou } \\
\text { durante a } \\
\text { sequência)). }\end{array}$ & $\begin{array}{l}\text { Pesquisador: Dentro desse gênero, a professora } \\
\text { privilegiou algumas partes, no ensino, no caso, } \\
\text { a professora privilegiou o ensino da estrutura, } \\
\text { privilegiou também a análise do gênero e, } \\
\text { assim, a professora acha que, em algum } \\
\text { momento, poderia ter explorado mais algum } \\
\text { outro aspecto ou um desses aspectos? } \\
\text { PL2: como falei pra você, eu privilegiei a } \\
\text { estrutura, porque eu queria automaticamente a } \\
\text { produção, e também agora eu poderia ter } \\
\text { explorado mais outros textos, se eu já tivesse } \\
\text { alguns arquivados, na nossa comunidade } \\
\text { escolar, ou poderia explorar também textos de } \\
\text { pessoas desconhecidas, claro. Agora tem muita } \\
\text { coisa envolvida e meu foco era na produção, aí } \\
\text { se eu explorar outros textos, talvez não seja o } \\
\text { suficiente para terminar naquele período. Ah, } \\
\text { mas é flexível! Sim, é flexível, mas a gente tem } \\
\text { a questão burocrática da escola. A educação, ela } \\
\text { funciona assim, mas tem toda uma burocracia, } \\
\text { com datas, com notas, com cadernetas, aí se }\end{array}$ & $\begin{array}{c}\text { atribuída à } \\
\text { necessidade de ensino } \\
\text { da professora e ao } \\
\text { cumprimento de } \\
\text { prescrições. }\end{array}$ \\
\hline
\end{tabular}

Persp. Online: hum \& sociais aplicada., Campos dos Goytacazes, 28 (10)80-97- 2020 seer.perspectivasonline.com.br 


\begin{tabular}{|c|c|c|}
\hline & $\begin{array}{l}\text { você pula aquilo ali, você tal dia precisa de } \\
\text { notas, tem que ter um planejamento, você tem } \\
\text { que ter tudo, se você não terminou, não vai ter o } \\
\text { que mostrar, não tem como ficar sem aquela } \\
\text { nota, nosso sistema não permite, e essas notas, } \\
\text { nos atrapalham muito. Elas não deixam a gente } \\
\text { livre, eu poderia até o final do ano trabalhar, } \\
\text { né? mas tem outras coisas além da sala de aula } \\
\text { para o professor, a gente tem que respeitar o } \\
\text { sistema, né? Eu poderia, em outras aulas, } \\
\text { melhorar, eu poderia focar também essa questão } \\
\text { de análise pra ver, pra analisar, pra estudar, para } \\
\text { melhorar o comportamento, pra ajudar, tem } \\
\text { muita coisa para ser ajudada, houve esse } \\
\text { privilégio nessa estrutura por conta da } \\
\text { produção porque precisava. }\end{array}$ & \\
\hline $\begin{array}{l}\text { Professora } \\
\text { organiza a } \\
\text { sala para que } \\
\text { os alunos } \\
\text { fizessem a } \\
\text { análise, além } \\
\text { da leitura. }\end{array}$ & $\begin{array}{l}\text { Pesquisador: No caso aqui, a gente percebeu } \\
\text { que a professora organizou a sala pra fazer de } \\
\text { fato, a análise com os alunos pra levar o gênero, } \\
\text { aí nesse momento eu lembro que a professora } \\
\text { fez e pediu para que os alunos lessem. Essa } \\
\text { prática da professora ler com os alunos, por que } \\
\text { a professora acha que é interessante? } \\
\text { PL2: Porque a aprendizagem é assim, eu tô } \\
\text { aprendendo, é claro, mas é mais direcionado a } \\
\text { eles. Se não houver essa ligação, apenas eu falo, } \\
\text { fica uma coisa rígida, eu diria monótona, aquela } \\
\text { coisa muito afastada, só o professor fala, só o } \\
\text { professor lê. E o aluno? Ele não é assim, aquele } \\
\text { aluno de ficar focado, ele não tem essa idade. } \\
\text { Assim, você tem que ir variando, dependendo } \\
\text { do foco que esse público tem, esse público, ele } \\
\text { precisa dessa interação, eu gosto... eu não leio o } \\
\text { texto, um lê uma linha, outro lê outra, eles } \\
\text { costumam ler, eu acho importante, porque eu } \\
\text { avalio a leitura, eles melhoram. Na outra escola } \\
\text { que eu trabalho, tinha um que tinha uma leitura } \\
\text { muito ruim, } 7^{\circ} \text { ano também, e ele passou, tudo } \\
\text { que eu "quem lê?" ele, "eu professora", e } \\
\text { eu tentando assim, de um jeito bem discreto, } \\
\text { fazendo algumas correções, pedi para que ele } \\
\text { respeitasse as pausas das vírgulas, dos pontos, e } \\
\text { ele foi observando. Ontem ele leu um texto, } \\
\text { assim, eu diria a vocês, maravilhosamente bem. } \\
\text { Aí por que? Porque também quando eles } \\
\text { interagem, na hora em que eles leem para o } \\
\text { grande grupo, eles tem uma preocupação, } \\
\text { eles não querem que os outros riam deles, eles } \\
\text { não querem ser ridicularizados, eles querem }\end{array}$ & $\begin{array}{l}\text { atribuída aos modos de } \\
\text { organização de } \\
\text { trabalho com o gênero } \\
\text { na sala de aula. }\end{array}$ \\
\hline
\end{tabular}

Persp. Online: hum \& sociais aplicada., Campos dos Goytacazes, 28 (10)80-97- 2020 seer.perspectivasonline.com.br 


\begin{tabular}{|l|l|}
\hline mostrar eficiência, aí eles começam a se \\
preocupar com a pronúncia correta da palavra, \\
eles começam a se preocupar com a leitura \\
correta da palavra, eles começam a ter essa \\
preocupação no momento em que eles são \\
alfabetizados. É claro, eles perdem a timidez, \\
eles melhoram muito essa oralidade deles, que é \\
muito importante, e isso dá um up na caixa de \\
autoestima e na própria aprendizagem. Quando \\
você pede para que ele leia, para que ele fale \\
para turma toda, tem uma atenção maior, tem \\
um ensino e aprendizagem, não adianta eu dizer \\
que não tem, só eu leio e só eu falando. Meu \\
Deus, parece um robô! É uma coisa, \\
misericórdia! Eu leio, eu falo, nunca eles vão \\
escutar. Não adianta você tem que trazê-los \\
para o assunto, você tem que trazê-los para \\
aula, você tem que trazê-los para situação \\
ocorrer, você tem que chamar a atenção para \\
eles despertarem. Se você não agir assim, eles \\
viram de costas.
\end{tabular}

Diferentemente de PL1, os dados gerados na ACS de PL2 contemplaram as 05 categorias por nós identificadas. Em relação à categoria (1) ressignificações atribuídas às necessidades de ensino da professora, com 02 ocorrências, os dados evidenciaram uma preocupação de PL2 com a exploração de uma dimensão específica do gênero: a forma ("eu privilegiei a estrutura porque eu queria automaticamente a produção [...]"). A categoria (4) ressignificações atribuídas à necessidade de contemplar as prescrições oficiais também contabilizou 02 ocorrências. Nesta, PL2 reconhece que nem sempre a escolha do gênero a ser estudado em sala é aleatória ou a critério do professor, pois embora haja certa flexibilidade curricular, o gênero a ser trabalhado já está prescrito ("primeiro porque está no programa, o programa ele é aberto, flexivel"). As demais categorias apresentaram 01 ocorrência cada. No que tange à categoria (2) ressignificações atribuidas aos modos de organização de trabalho com o gênero na sala de aula, parecia evidente, segundo PL2, a ideia de flexibilização do planejamento para atingir os objetivos pretendidos a depender do público-alvo ("tem que ter um planejamento" / "assim, você tem que ir variando, dependendo do foco que esse público tem [...]'). Já no que concerne à categoria (3) ressignificações atribuídas à relação do gênero com os usos da língua fora da escola, a preocupação de PL2 era a mesma de PL1: estabelecer uma relação das práticas de linguagem escolares com as práticas de linguagem de outros espaços sociais ("pra publicação, pra explanação, pra conhecimento, pra tudo! Pra ir além da escola!"). Por fim, a categoria (5) ressignificações atribuidas às potencialidades do gênero no ensino de línguas remete às reflexões feitas por PL2 acerca da dinamicidade do gêneros e das possibilidades de aprendizagem que ele pode proporcionar no ensino de língua (" $[. .]$. gênero é muito dinâmico, o gênero é extremamente dinâmico [...] e dá muita abertura para novas ideias $[\ldots])$. 


\section{CONCLUSÕES}

O ponto de partida deste estudo foi a premissa de que as ações docentes em sala de aula estão situadas entre o que lhes é prescrito enquanto trabalho e aquilo que eles (docentes) consideram importante para a aprendizagem dos seus alunos. Desse modo, os dados decorrentes das ACS com as duas professoras nos possibilitaram desvelar um pouco os bastidores do agir didático com gêneros. Mais do que isso! Nós demos "voz" às professoras. As categorias referentes aos processos de ressignificação apontaram para algumas nuances do trabalho com o gênero que, possivelmente, seriam invisibilizadas na perspectiva apenas do pesquisador observador, tais como a necessidade de diagnosticar os conhecimentos dos alunos sobre o gênero e, consequentemente, identificar as reais necessidades de aprendizagem, bem como a importância de se utilizar recursos didáticos/tecnológicos apropriados à abordagem do gênero. Outrossim, pudemos perceber que já há, por parte das professoras, uma compreensão acerca das potencialidades do gênero para o ensino de língua. Elas também revelaram uma aparente consciência acerca da relação que deve ser estabelecida entre o ensino de gênero na sala de aula e as práticas de linguagem que ocorrem fora da escola, muito embora isso ainda não tenha sido totalmente incorporado às suas práticas de ensino. Dado o exposto, acreditamos que os saberes docentes em relação a $o$ que e como ensinar são atravessados não só pela ciência e pelo coletivo de trabalho, mas também por trajetórias singulares, únicas. Isso, talvez, explique os movimentos de tensão e incertezas no processo de sedimentação dos saberes escolares sobre o gênero nas práticas de ensino.

\section{REFERÊNCIAS}

AMIGUES, René. Trabalho do professor e trabalho de ensino. In: MACHADO, Anna Rachel (org.). O ensino como trabalho: uma abordagem discursiva. Londrina: Eduel, 2004, p. 35-54.

BAKHTIN, Mikhail. Os gêneros do Discurso. In: Estética da criação verbal. 4. ed. São Paulo: Martins Fontes, 2003, p. 261-306.

BRONCKART, Jean-Paul. Por que e como analisar o trabalho do professor. In: Atividades de linguagem, discurso e desenvolvimento humano. Campinas, SP: Mercado de Letras, 2006. Pp.203-229.

CLOT, Yves. Métodos. In: Vozes, 2007. pp.125-150.

A função psicológica do trabalho. Petrópolis, RJ:

DOLZ, Joaquim; NOVERRAZ, Michele e SCHNEUWLY, Bernard. Sequências didáticas para o oral e a escrita: apresentação de um procedimento. In: SCHNEUWLY, Bernard. DOLZ, Joaquim. Gêneros orais e escritos na escola. Campinas, SP: Mercado de Letras, 2004. p.95-128.

DOLZ, Joaquim e SCHNEUWLY, Bernard. Gêneros e progressão em expressão oral e escrita-elementos para reflexões sobre uma experiência suíça (francófona) In: SCHNEUWLY, Bernard. DOLZ, Joaquim. Gêneros orais e escritos na escola. Campinas, SP: Mercado de Letras, 2004. p. 35-60.

Persp. Online: hum \& sociais aplicada., Campos dos Goytacazes, 28 (10)80-97- 2020 
LIMA, Gustavo Henrique da Silva Lima. O que eu ensino quando ensino gêneros? Um estudo sobre as ressignificações do agir didático do professor de língua portuguesa. (Tese de Doutorado). Programa de Pós-Graduação em Letras. UFPE. Recife, 2016. $284 f$.

MACHADO, Anna Rachel et al. Relações entre linguagem e trabalho educacional: novas perspectivas e métodos no quadro do Interacionismo Sociodiscursivo. In: MACHADO, Anna Rachel (org). Linguagem e educação: o trabalho do professor em uma nova perspectiva. Campinas, SP, Mercado de Letras, 2009. pp. 15-30.

MACHADO, Anna Rachel. Ensino de gêneros textuais para o desenvolvimento do professor e de seu trabalho. In: SERRANI, Silvia (org.). Letramento, discurso e trabalho docente. Vinhedo: Editora Horizonte, 2010. p. 160-171.

MARCUSCHI, Luiz Antônio. Gêneros textuais: definição e funcionalidade. In: DIONÍSIO, A. P; MACHADO, A. R; BEZERRA, M. A. (Orgs.). Gêneros textuais \& ensino. São Paulo: Editora Lucerna, 2002, p. 19-36.

MARCUSCHI, Luiz Antônio. Gêneros textuais no ensino de língua. In: Produção textual, análise de gêneros e compreensão. São Paulo: Parábola Editorial, 2008, p. 145-226.

MOREllato, J. L. H.; SILVA, M. P. A. C. DA; OLIVEIRA CUNHA, T. C.; PUGLIA, V. M. S. A ATUAÇÃO DO PEDAGOGO NOS ESPAÇOS NÃO ESCOLARES NO MUNICÍPIO DE CAMPOS DOS GOYTACAZES, RJ. Humanas \& Sociais Aplicadas, v. 10, n. 27, p. 63-83, 21 fev. 2020.

SANTOS, B. B. de M. A prática docente no Ensino Médio: ressignificando os conhecimentos linguísticos. Dissertação (Mestrado em Linguística). Recife: UFPE, 2017.

SCHNEUWLY, Bernard e DOLZ, Joaquim. Os gêneros escolares-das práticas de linguagem aos objetos de ensino. In: SCHNEUWLY, Bernard. DOLZ, Joaquim. Os gêneros escolares - das práticas de linguagem aos objetos de ensino. In: Gêneros orais e escritos na escola. Campinas, SP: Mercado de Letras, 2004. p. 61-78.

SCHNEUWLY, Bernard. Le travail enseignant. In: SCHNEUWLY, Bernard; DOLZ, Joaquim. Des objets enseignés en classe de français: le travail de l'enseignant sur la rédaction de textes argumentatifs et sur la subordonnée relative. Genève: Presses Universitaires de Rennes, 2009. p. 29-43.

Persp. Online: hum \& sociais aplicada., Campos dos Goytacazes, 28 (10)80-97- 2020 seer.perspectivasonline.com.br 